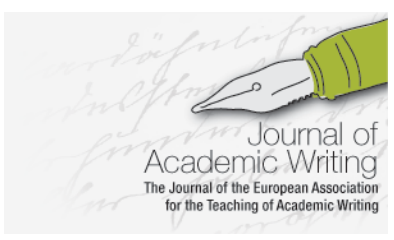

Journal of Academic Writing

Vol. 11 No 1 Summer 2021, pages 92-106

https://doi.org/10.18552/joaw.v11i1.658

\title{
The Relationship between Comfort with Writing and Comfort Working with Numbers in STEM
}

\author{
Justin Nicholes \\ University of Wisconsin-Stout, USA
}

\begin{abstract}
Informed by writer-identity theory explaining links between emotion and identity, this study explores college STEM students' feelings of comfort pertaining to math literacy, quantitative literacy, writing in STEM, and writing in general. Survey data from STEM majors $(\mathrm{N}=134)$ was analyzed with Spearman rho tests of association. Results indicated that feelings of comfort working with numbers was significantly associated with comfort writing about numbers ( $\mathrm{rs}=$ $.504, p<.001$ ); comfort writing about numbers was significantly associated with comfort writing in STEM ( $r s=.265, p=.002)$; and comfort writing in STEM was significantly associated with comfort writing in general $(r s=.558, p<.001)$. This study suggests links between positive emotional experiences, which are implicated in identity performances, of quantitative writing, disciplinary writing, and writing in general. Future research on emotional experience and writer identity across the curriculum and in the disciplines is called for.
\end{abstract}

\section{Introduction}

Studies underscoring the importance of students' emotional experiences across disciplines have gained momentum over the last several years (Linnenbrink-Garcia \& Pekrun, 2011). Defined here, emotional experience comprises feelings and emotions regarding learning and being in learning situations; while feelings denote potentially metacognitive emotional experiences allowing self-monitoring and reflection, emotions 'control action that leads to engagement in or suspending of action related to learning' (Efklides \& Volet, 2005, pp. 377378). In a study of 134 adult learners, Brand et al. (2007) reported that students' moods affected learning achievement and transfer. In particular, negative moods and anticipation of disappointment stymied outcomes (Brand et al., 2007). In another study, Robbins et al. (2009) analyzed 107 studies on college intervention strategies' impact on retention. The researchers determined that emotions affected retention, with emotional control impacting academic performance, and academic performance impacting retention (Robbins et al., 2009). Prior research, then, highlights students' emotional experiences at levels important in U.S. higher education and plausibly other comparable HE systems. At the classroom level, emotional experiences influence learning and engagement. At the institutional level, emotional experiences influence retention.

Writing-studies researchers and instructors should make note of emotional experiences' relationship to writing and writer identity. Initiatives and priorities in higher education reflect interest in how students feel being at college and completing college work. Belli (2016) argues that this is the case because of higher education's embracing of positive psychology (the scientific study of happiness) and positive education (the practice of teaching well-being). For Belli, we in writing studies should be aware of the increasing attention paid to college students' emotional experiences.

Another reason to pay attention to our students' emotional experiences is that writing is emotional. Wendy Bishop (1993, p. 503), noting writing as emotional, argued that 'In composition studies, we should be paying attention to issues of affect'. For Micciche (2007), 
emotion is both integral and inseparable from meaningful communication. This is also the assumption of Hanauer's (2012) meaningful literacy approach, where writers' emotional and autobiographical selves occupy a writing classroom's center. Emotions imbue writing processes (Ballenger \& Myers, 2019; Prebel, 2016) and impact overall writer development (Kaufman, 2017).

For French (2018), emotions define students' very understandings of academic writing and, consequently, their academic identities. Emotions also explain students' relationships with grades, which students index when constructing academic identities (Inman \& Powell, 2018). Driscoll and Powell (2016), in a longitudinal study of 13 writers, reported that disruptive emotions occurred more than generative emotions and affected writing-skill and writingknowledge transfer. Writing instructors, Driscoll and Powell urge, should pay attention to how emotional experiences affect transfer and writer identities. This study explores the interplay between emotional experience and STEM students' writer identity formation through the lens of writer identity theory.

\section{Theoretical framework}

Writer identity theory (Ivanič, 1998) explains the association of emotional experience, in particular feeling comfort, and how writers see and perform themselves as writers. Ivanič (1998) theorizes writer identity as including four main aspects, outlined in Table 1.

\section{Table 1}

Writer Identity Theory

\section{Aspects of the identity of an actual writer writing a particular text \\ 1. Autobiographical Constructed and constantly changing identity which people bring with Self $\quad$ them to any act of writing, shaped by prior social and discoursal history. The self that produces the self-portrait rather than self that is portrayed. \\ 2. Discoursal Self The impression-often multiple, sometimes contradictory-writers consciously or unconsciously convey of themselves in a particular composition. Constructed in the act of writing through the discourse characteristics of a text, which relate to values, beliefs, and power relations in the social context in which the composing happened. \\ 3. Self as Author Writer's relative authoritativeness toward a constructed text. Often a product of autobiographical self and aspect of discoursal self.}

\section{Abstract, prototypical identities available in the sociocultural context of writing \\ 4. Possibilities for Shaped by and shape writers' aspects of identity. The several socially Selfhood available possibilities for selfhood (several ways of doing the same thing) in any institution. The relative privileging among these possibilities shape and constrain people who are writing actual texts.}

Note. Adapted from Writing and Identity: The Discoursal Construction of Identity in Academic Writing, by Ivanič, R., 1998, pp. 23-30.

Ivanič (1998) differentiates among these aspects of writer identity as a heuristic for understanding what writers mean when discussing their writer identities. These aspects of writer identity, according to Ivanič, change over time and sometimes radically from one writing situation to another.

One way Ivanič (1998) codes the dissonance writers feel in relation to aspects of their writer identities is through isolating statements regarding comfort. One participant, Rachel, frequently 
referred to comfort in her interview and writing data; in referring to a composition Ivanič (1998, p. 158) labels a social-work essay, Rachel wrote,

I felt like I was playing a game. Like, I mean, I might not even be interested in social work, but I felt like I had to put that in ... in other words playing a role. It's quite easy to kind of play a role and lie ... because I was playing a role I wasn't being myself ... so that's why I felt uncomfortable [emphasis added].

Ivanič refers to feelings of comfort and discomfort while interpreting Rachel's and other participants' data. Theoretically, then, I argue here that exploring identity in relation to expressed feelings of comfort and discomfort promises new insight particularly, here, into college students' writing experiences.

Writing-related emotional experiences' association with writer identities has been argued beyond the research of Ivanič (1998). As noted earlier, French (2018) urges writing instructors to consider how emotions come to impact students' conceptions of academic writing and their academic identities, and Driscoll and Powell (2016) underscore the influence of emotion on writing transfer and senses of writer selves.

The more specific emotional experience of comfort has also appeared apart from Ivanič (1998). In a foundational work, Bartholomae (1986) argues that 'students have to appropriate (or be appropriated by) a specialized discourse, and they have to do this as though they were easily and comfortably [emphasis added] one with the audience, as though they were members of the academy' (pp. 4-5). Referring to activities assisting identity negotiation, Corkery (2005, p. 51) reasons that 'literacy narratives can offer students a chance to adjust their self-images to place themselves comfortably [emphasis added] within their new academic community'. Comfort, then, arises among students who can envision belonging and who identify with so-called academic literacy (Bartholomae, 1986; Corkery, 2005). More recently, like Prebel (2016), Hunma et al. (2019, p. 90) discuss a 'pedagogy of discomfort' employed to disrupt South African student writers' senses of coherent selves, something the authors attempted to explore via students' reflective essays about their places in a higher education system they describe as turbulent. In these reports, comfort and discomfort contribute to constructions of academic selves.

Feelings of comfort have additionally appeared in STEM-student literature. van der Hoeven Kraft et al. (2011), for instance, urges STEM instructors to attend to geoscience students' affective experiences to support achievement. One reason to encourage positive emotional experiences in education generally, and STEM specifically, may be that emotions are transmittable: in one study, Hazari et al. (2017) report that STEM students' feelings of interest were contagious and capable of impacting students' intentions to pursue STEM careers. Florence and Yore (2004) note that expert scientists possess distinct cognitive, metacognitive, and emotional qualities. In their words, 'Expert science writers are comfortable [emphasis added] within their respective discourse communities; they use their knowledge of genre and audience to construct new science ideas and insights' (Florence \& Yore, 2004, p. 645). Further emphasizing the importance of comfort, research on STEM-student engagement, belonging, and persistence have included data-collection instruments with survey items meant to collect data on this feeling; for instance, Trujillo and Tanner (2014) explore the role of affect in STEM students' STEM identities. The researchers measured biology-student participants' senses of belonging in STEM in part with the item When I am in a math setting, I feel comfortable (Trujillo \& Tanner, 2014). In another study of STEM-student persistence, Findley-Van Nostrand and Pollenz (2017) ask what psychosocial mechanisms undergird persistence in STEM majors. Affect, measured in part by the survey item I feel comfortable, was an important contributor to students' senses of belonging in STEM and thus STEM students' desires to persist (FindleyVan Nostrand \& Pollenz, 2017). The emotional experience of feeling comfort, then, is important for understanding engaging classroom experiences and STEM students' persistence decisions, as emotions have been implicated as possibly impacting academic performance and retention (Robbins et al., 2009). 
In the present study, to emphasize the significance of emotion, I define writer identity as both the emotional sense writers have of themselves as writers and the emotional performances of those selves.

\section{STEM writers, quantitative literacy, and emotional experiences}

Scholars have traditionally categorized STEM fields as differing from others, such as from humanities fields (Becher, 1994). Recently, in explaining the nature of STEM and how its members understand STEM fields, a study by Reinholz et al. (2019) surveyed 78 STEM researchers and professors. Participants identified significant overlap among STEM fields, including (a) high-enrollment introductory service courses driving lower-division curricula; (b) White men holding most power; and (c) reputations as inaccessible and rigorous, with introductory courses serving as gatekeepers (Reinholz et al., 2019). Importantly, Reinholz et al. (2019) report differences among STEM disciplines and subdisciplines, regarding gender balance, feelings of elitism, and emphases on empirical versus theoretical issues. Despite challenges in categorization, STEM students receive much attention in U.S. higher education, partly because of then-US President Obama's 2012 assessment that one million additional STEM-major graduates were necessary to keep the U.S. economy internationally competitive (President's Council of Advisors on Science and Technology (PCAST), 2012). Encompassing one-third of degrees conferred (STEM education data, 2014), STEM majors warrant further attention from the field of writing studies.

Among other attributes, what has traditionally distinguished STEM fields from others has been STEM disciplines' valuing of quantities (Becher, 1994). Science literacy, in fact, has been described as critically involving quantitative literacy (Meisels, 2010). Quantitative literacy can be defined as 'an everyday understanding of mathematics' and a feeling of being capable of functioning in situations where numerical information is required to solve problems (Wilkins, 2000, p. 406). Understood as requiring skills featured in English composition, mathematics, and content coursework (Miller, 2010), quantitative literacy is valued in writing-related initiatives (Feigenbaum, 2015; N. D. Grawe \& Rutz, 2009; P. H. Grawe \& Grawe, 2014; Hillyard, 2012) and in composition-instructor training (Wolfe, 2010), and it has been researched as related to STEM students' disciplinary identities (Nicholes, 2019).

Relevant research further explains the significance of STEM writers' emotional experiences. Scientists using English as an additional language to write reports have expressed negative emotions related to the process (Keranen et al., 2012). The statistically significant difference in emotional experience using English as an additional language versus using a scientists' first language to write scientifically has been quantified in two influential studies (Hanauer \& Englander, 2011; Hanauer et al., 2019). Lin et al. (2012) stress the importance of positive emotional experiences to boost students' future public engagement with science, while Hanauer and Dolan (2014) researched the association of STEM students' ownership for scientific-writing projects and emotional experiences. Ownership, comprising emotional experiences toward a project, has been described as critical in understanding STEM-student persistence (Hanauer \& Dolan, 2014). Once again, emotional experiences are implicated at classroom and institutional levels.

Recent scholarship by Emerson (2016, 2019) emphasizes that we in writing studies, and in writing across the curriculum/in the disciplines (WAC/WID) particularly, still have much to learn about how scientists think, and think of themselves, as writers. In a study of science-writer identities, Emerson (2016, p. 16) reports that 'Scientists may not always identify as writers, and some scientists may not consciously recognise that their professional lives are constructed on written texts; the interviews in this study showed that most had never discussed their writing practices and experiences'. Emerson (2019) has also argued that STEM students may hold negative feelings toward science writing as a result of schooling experiences causing low selfefficacy beliefs. The present study extends the work of Emerson by measuring the degree to which aspects of STEM majors' writer identities are associated. 


\section{Research question}

In this study, I draw on Du Bois's (2007) concept of stancetaking. For Du Bois (2007, p. 173), 'Stance is an act of evaluation owned by a social actor'. The act of stancetaking evaluates an object, positions a subject, and aligns subjects with perceived aspects of communities and concepts. Students' responses on this study's survey, then, are conceptualized as individual instances of stancetaking in relation to aspects of students' majors specifically and of their lived experiences generally. These stances index aspects of participants' constantly changing writer identities.

All this said, the study pursues the following research question: Will students' degree of quantitative-literacy comfort be associated with their degree of writing comfort?

\section{Methods}

Ethical principles outlined in The Belmont Report (1979)—respect for persons, beneficence, justice-directed all decisions related to participants and their data.

This study was issued exempt status by the Institutional Review Board (IRB) of Indiana University of Pennsylvania, in Pennsylvania, USA. The university is a public, comprehensive, research-based university, with about 12,000 undergraduate and graduate students enrolled in total per year. The institution funded a Writing Across the Curriculum (WAC) program, which offered interested faculty members across campus workshops on approaches to using writing in non-writing courses. Writing courses at the institution included two mandatory first-year general-education writing courses, called Composition 1 and Composition 2, which introduce students to personal and academic writing and, increasingly, offer focused practice in summarizing, synthesizing, and using secondary research in writing. While Composition 1 and Composition 2 are required courses for students, students in any given class focus on a range of different majors. Therefore class assignments are not discipline-specific; disciplinary writing, then, typically happens in students' major courses if a professor chooses to incorporate it, or through individual, sometimes informal research assistance that students give to professors in labs. The fact that writing courses are often viewed as separate from the writing students actually do with STEM professors offers a context for understanding students' writing comfort in both general and disciplinary contexts.

\section{Study design and hypotheses}

To explore results, a Friedman test of differences was used to check for differences among reported comfort; Kendall's W coefficient of concordance was used to measure effect size of any difference from the Friedman. Wilcoxon signed-ranks tests of difference were used to make post hoc comparisons, using a Bonferroni corrected $p$ value of .008 to indicate statistical significance. To further explore the data, a Kruskal-Wallis nonparametric test was also conducted to test for statistically significant differences among STEM majors and levels of education.

To answer this study's guiding research question, a quantitative design using inferential association tests was used. Shapiro-Wilk tests of normality for all items showed a significance value $(p<.05)$ indicating that Spearman rho tests of association best fit the data. 
Figure 1.

Research question data-analysis design.

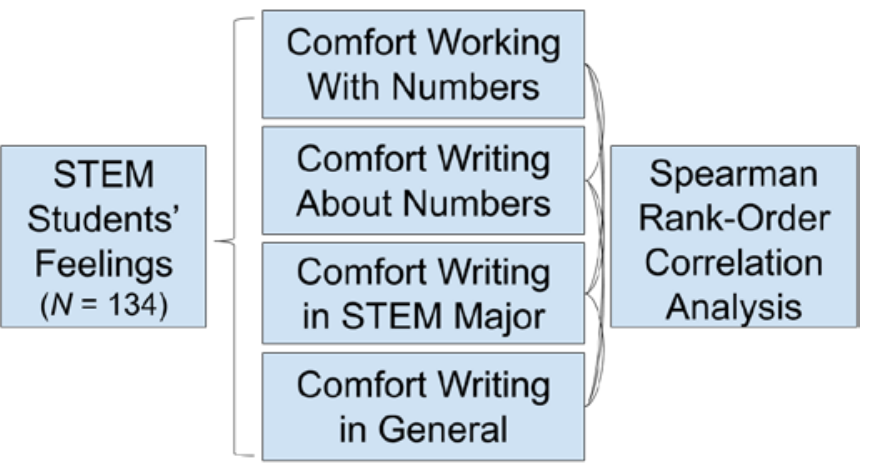

Hypotheses for this study can be stated as follows:

- Null: No statistically significant association exists between quantitative-literacy and writing comfort.

- Alternative: A statistically significant, positive association exists among quantitativeliteracy comfort and writing comfort.

\section{Participants}

With IRB approval, I invited participants from STEM-major mathematics courses and writingstudies listservs. I contacted STEM math professors to ask if I could invite students to participate at the beginning of their classes. Students received paper copies of the survey, the first page being an informed-consent form. Additionally, with IRB approval, I posted a call for professors to forward the survey to their students on writing-studies listservs. The table below details characteristics of participants who completed the survey $(N=134)$.

\section{Table 2}

Participants' Characteristics

\begin{tabular}{|l|l|l|}
\hline Category & Characteristic & Number \\
\hline \multirow{5}{*}{ STEM Major } & Biochemistry & 8 \\
\hline & Biology & 30 \\
\hline & Chemistry & 8 \\
\hline & Computer Science & 28 \\
\hline & Engineering & 1 \\
\hline & Geoscience \& Geography & 12 \\
\hline & Mathematics & 29 \\
\cline { 2 - 3 } & Natural Science & 9 \\
\hline & Physics & 6 \\
\cline { 2 - 3 } & Psychology & 1 \\
\hline \multirow{5}{*}{ Sevel of Education } & Graduate & 24 \\
\hline & Undergraduate & 110 \\
\hline \multirow{5}{*}{ Age } & Female & 59 \\
\hline & Male & 72 \\
\hline & Preferred Not to Answer & 3 \\
\hline & $18-25$ & 115 \\
\hline & $26-36$ & 19 \\
\hline
\end{tabular}




\section{Materials}

The survey underwent a multi-stage validity process. A review of education and writing-studies literature on emotional experiences and the feeling of comfort specifically was conducted. Items in the survey were composed with reference to other studies' items and workshopped with fellow researchers in composition and applied linguistics. This process enabled content validity and readability checks and resulted in the following items:

What is your comfort level with each of these?

- Working with numbers

- Writing about numbers

- Writing essays in my major

- Writing in general

The following rating scale was used: $1=$ Not at all comfortable; 2 = Somewhat uncomfortable; $3=$ Neither comfortable nor uncomfortable; 4 = Somewhat comfortable; $5=$ Very comfortable. See Appendix A for the survey.

\section{Results}

Table 3

Descriptive Statistics for Comfort Items

\begin{tabular}{|c|c|c|c|c|c|}
\hline \multirow[b]{2}{*}{ Item } & \multirow[b]{2}{*}{$M$} & \multirow[b]{2}{*}{ Mdn } & \multirow[b]{2}{*}{$S D$} & \multicolumn{2}{|c|}{ 95\% Confidence Interval } \\
\hline & & & & Lower & Upper \\
\hline Comfort Working With Numbers & 4.28 & 4.50 & .881 & 4.13 & 4.43 \\
\hline Comfort Writing About Numbers & 3.90 & 4.00 & .869 & 3.75 & 4.04 \\
\hline Comfort Writing in STEM Major & 4.04 & 4.00 & .908 & 3.89 & 4.20 \\
\hline Comfort Writing in General & 4.22 & 4.00 & .971 & 4.06 & 4.39 \\
\hline
\end{tabular}

Before addressing the study's guiding research question, a Friedman test of differences among reported comfort was used; the test rendered a Chi-square value of 25.87, which was significant $(p<.001)$; Kendall's W coefficient of concordance was .064, indicating a small effect size (Cohen, 1988). Wilcoxon signed-ranks tests of difference were used to make post hoc comparisons, using a Bonferroni corrected $p$ value of .008 to indicate statistical significance. Wilcoxon tests indicated,

1. Comfort working with numbers $(M d n=4.50)$ was significantly higher than comfort writing about numbers $(M d n=4.00), Z=-5.04, p<.001, r=.44$, a medium effect size (Cohen, 1988)

2. Comfort writing in general $(M d n=4.00)$ was significantly higher than comfort writing about numbers (Mdn = 4.00), $Z=-3.18, p=.001, r=.28$, a small effect size (Cohen, 1988).

Table 4

Spearman Rho Associations for Comfort Items

\begin{tabular}{|l|l|l|l|l|}
\hline & 1 & 2 & 3 & 4 \\
\hline 1. Comfort Working With Numbers & -- & $.504^{\star}$ & -.030 & -.022 \\
\hline 2. Comfort Writing About Numbers & & -- & $.265^{\star \star}$ & .169 \\
\hline 3. Comfort Writing in STEM Major & & & -- & $.558^{\star}$ \\
\hline 4. Comfort Writing in General & & & \multicolumn{2}{|l|}{} \\
\hline
\end{tabular}

$* p<.01$

${ }^{* *} p<.05$ 
A Spearman's rho revealed a statistically significant, positive relationship between,

1. Comfort working with numbers and comfort writing about numbers, $r_{\mathrm{s}}=.504, p<.001$. The effect size for this relationship was medium to large (Cohen, 1988).

2. Comfort writing about numbers and comfort writing in STEM major, $r_{\mathrm{s}}=.265, p=.002$. The effect size for this relationship was small to medium (Cohen, 1988).

3. Comfort writing in STEM major and comfort writing in general, $r_{\mathrm{s}}=.558, p<.001$. The effect size for this relationship was large (Cohen, 1988).

As a follow-up test to explore the data, a Kruskal-Wallis nonparametric test was conducted to test for statistically significant differences among STEM majors and levels of education. The test indicated that STEM major groups differed on comfort working with numbers, $X^{2}(7, N=$ $134)=23.35, p=.001$, but in no other comfort item. Post hoc Mann-Whitney tests compared the groups on comfort working with numbers, using a Bonferroni corrected $p$ value of .002 to indicate statistical significance. The mean rank for comfort working with numbers of mathematics majors $(23.05, n=28)$ was significantly higher than that of geoscience majors (12.23, $n=11), z=-3.07, p=.002, r=.53$, a large effect size (Cohen, 1988).

Three further tests yielded results without statistical significance. A Kruskal-Wallis test was conducted to test for differences among level of education, age, and self-identified gender of STEM majors regarding their reported degrees of comfort with quantitative literacy and writing, yielding no statistically significant result.

\section{Summary of findings}

- STEM majors' reported comfort working with numbers, writing about numbers, writing in STEM, and writing in general largely ranged between somewhat comfortable to very comfortable.

- STEM majors reported feeling much more comfortable both working with numbers and writing in general than they reported feeling about writing about numbers.

- The more students reported feeling comfort working with numbers, the more they reported feeling comfort writing about numbers.

- The more students reported feeling comfort writing about numbers, the more they reported feeling comfort writing in their STEM major.

- The more students reported feeling comfort writing in their STEM major, the more they reported feeling comfort writing in general.

- Mathematics majors reported especially more comfort working with numbers than did geoscience majors.

- When grouped by level of education, age, and gender, STEM majors did not differ in comfort toward numbers or writing.

\section{Discussion}

This study set out to address the research question, Will students' degree of quantitativeliteracy comfort be associated with their degree of writing comfort? Writer identity theory explains emotional experiences as informed by and indexical of writer identities (French, 2018; Hunma et al., 2019; Ivanič, 1998) and frames this associational quantitative-design study. STEM-student participants in this study are understood as taking stances (Du Bois, 2007) in their survey responses about academic activities and, in so doing, offering glimpses of aspects of their performed academic identities. Further, comfort has been indicated here as arising among students who can envision belonging to and who identify with so-called academic literacy (Bartholomae, 1986; Corkery, 2005). Therefore, the emotional experience of feeling comfort, in the present study, is presented as important for understanding classroom experiences that engage students, and STEM students' persistence decisions. In the present study, to emphasize the significance of emotion, I have defined writer identity as both the emotional sense writers have of themselves as writers and the emotional performances of those selves. 
This said, main findings indicate some evidence that STEM majors, as represented in this sample, feel generally comfortable with quantitative literacy, science literacy, and general writing literacy as aspects of their academic identities. Evidence exists here, though, that STEM students may feel less comfortable writing about numbers than they feel working with numbers and writing in general. This suggests that STEM students' identities as math literate may clash with their identities as quantitatively literate: They present themselves as feeling comfortable doing and understanding math but less strongly as they present themselves as students who feel comfortable reporting on those numbers in writing.

Additionally, findings here offer evidence that STEM students' identities as math literate relate to their identities as both quantitatively-literate and STEM-writing literate. Finally, students' writer identities in general relate to their more specific STEM-writer identities. Math-literate feelings and, as a result, more seemingly possible subject positions as math literate were especially striking among math majors when compared to geoscience majors. These associations came despite STEM students' ages, levels of education, and self-reported gender.

These findings extend earlier scholarship on writers' emotional experiences, writer identities, and college STEM writers. This study, which highlights the importance of feelings toward math literacy, supports the notion that one distinguishing characteristic of STEM fields may be its emphasis on quantities (Becher, 1994). It also, though, adds additional insight to Reinholz et al.'s (2019) conclusion that STEM does not represent a monolith despite significant STEM-field overlap: Math majors, maybe unsurprisingly, claimed significantly more comfort working with numbers than did geoscience majors. More significantly for writing-studies and WAC/WID scholarship, this study extends the scholarship of Emerson $(2016,2019)$, who noted that we still lack data on how scientists think of themselves as writers. The present study suggests that STEM students' identity aspects are associated in complex ways, such that, when prompted to think about it, STEM students' comfort doing the science, collecting and analyzing the quantities so to speak, outweighs their comfort writing about those quantities. Yet the more comfortable they felt working with numbers, the more comfortable they felt writing about them and in STEM.

This study's methodological strengths include the quantification of STEM students' relative feelings of comfort across aspects of their academic and disciplinary lives. This has allowed for an additional approach to understand the different aspects of STEM writers' identities. While the important work of Emerson (2016) has indicated that scientists see themselves first as scientists and, within that science identity, as then writers, the present study offered a quantitative design enabling inferential statistical analysis to conclude whether those differences and associations reach statistical significance.

Of course, the findings discussed here must be understood in relation to the study's limitations. This study was limited by asking STEM majors about feelings of general aspects of their academic lives. I was not able to go deeper, as Driscoll and Powell (2016) did, to associate feelings with specific texts. In addition, participants were mainly from one institution and spread across various majors, limiting generalizability. Concerning the survey, a limitation concerns the use of single items instead of multi-point scales to measure comfort.

\section{Conclusion}

This study posed the question, Will students' degree of quantitative-literacy comfort be associated with their degree of writing comfort? The short answer is, yes: STEM students' math literacy and quantitative-writing literacy comfort relate to writing comfort. Findings justify rejection of the null hypothesis, and acceptance of the alternative hypothesis, that a statistically significant association exists between quantitative-literacy and writing comfort. The findings here support the use of writer identity theory that takes emotional experiences as shaping and referring to aspects of identity, and quantitative-design approaches allow for inferential statistics to complement qualitative-inquiry findings on this issue.

The value of this study for writing instructors and program administrators comes from it indicating discipline-related and writing-related emotional experiences as significantly 
associated. Concerning STEM writers in our classes, and in STEM programs, math and quantitative literacy seem like promising initiatives to continue to support. More generally, it seems important to identify other aspects of students' majors in addition to and outside of STEM that are identified as critical to participation in these communities. Indeed, as Tinto's (2017) persistence theory explains, numerous interrelated variables impact students' decisions to remain in college, such as feeling of belonging, self-efficacy, and perceptions of their curricula as actually useful for their futures.

Future scholarship, then, can extend this research in several ways. Additional research seems to be needed on the emotional experiences STEM students hold toward math literacy, and math literacy's association with feelings of writing comfort and other emotional experiences, such as that arising from self-efficacy beliefs. In terms of future quantitative-design studies, more work is needed to construct survey instruments. Qualitative inquiry seems to be needed to further flesh out aspects of comfort, in order to provide justification for the design and validation of emotional-experience instruments. Exciting work on department- and disciplinary-specific threshold concepts, such as that by Wardle et al. (2018), may also assist in identifying salient aspects of disciplines and, consequently, disciplinary-identity subject positions in relation to which students may take stances. This will assist in measuring associations among feelings and identity aspects valued or necessary for meaningful community participation. 


\section{References}

Ballenger, B., \& Myers, K. (2019). The emotional work of revision. College Composition and Communication, 70(4), 590-614.

Bartholomae, D. (1986). Inventing the university. Journal of Basic Writing, 5(1), 4-23.

Becher, T. (1994). The significance of disciplinary differences. Studies in Higher Education, 19(2), 151. https://doi.org/10.1080/03075079412331382007

Belli, J. (2016). Why well-being, why now?: Tracing an alternate genealogy of emotion in composition. Composition Forum, 34. https://compositionforum.com/issue/34/whywell-being.php

The Belmont Report. (1979). U.S. Department of Health \& Human Services. http://www.hhs.gov/ohrp/regulations-and-policy/belmont-report/index.html

Bishop, W. (1993). Writing is/and therapy?: Raising questions about writing classrooms and writing program administration. Journal of Advanced Composition, 13(2), 503-516.

Brand, S., Reimer, T., \& Opwis, K. (2007). How do we learn in a negative mood? Effects of a negative mood on transfer and learning. Learning and Instruction, 17(1), 1-16. https://doi.org/10.1016/j.learninstruc.2006.11.002

Cohen, J. (1988). Statistical power analysis for the behavioral sciences (2nd ed.). Lawrence Erlbaum.

Corkery, C. (2005). Literacy narratives and confidence building in the writing classroom. Journal of Basic Writing, 24(1), 48-67.

Driscoll, D. L., \& Powell, R. (2016). States, traits, and dispositions: The impact of emotion on writing development and writing transfer across college courses and beyond. Composition Forum, 34. http://compositionforum.com/issue/34/

Du Bois, J. W. (2007). The stance triangle. In R. Englebretson (Ed.), Stancetaking in discourse: Subjectivity, evaluation, interaction (pp. 139-182). John Benjamins.

Efklides, A., \& Volet, S. (2005). Emotional experiences during learning: Multiple, situated and dynamic. Learning and Instruction, 15(5), 377-380.

https://doi.org/10.1016/i.learninstruc.2005.07.006

Emerson, L. (2016). The forgotten tribe: Scientists as writers. The WAC Clearinghouse.

Emerson, L. (2019). 'I'm not a writer': Shaping the literacy-related attitudes and beliefs of students and teachers in STEM disciplines. In V. Prain \& B. M. Hand (Eds.), Theorizing the future of science education research: Contemporary trends and issues in science education (pp. 169-187). Springer.

Feigenbaum, P. (2015). Rhetoric, mathematics, and the pedagogies we want: Empowering youth access to twenty-first century literacies. College English, 77(5), 429-449.

Findley-Van Nostrand, D., \& Pollenz, R. S. (2017). Evaluating psychosocial mechanisms underlying STEM persistence in undergraduates: Evidence of impact from a six-day pre-college engagement STEM academy program. CBE-Life Sciences Education, 16, 1-15. https://doi.org/10.1187/cbe.16-10-0294

Florence, M. K., \& Yore, L. D. (2004). Learning to write like a scientist: Coauthoring as an enculturation task. Journal of Research in Science Teaching, 41(6), 637-668. https://doi.org/10.1002/tea.20015 
French, A. (2018). Academic writing: Anxiety, confusion and the affective domain: Why should subject lecturers acknowledge the social and emotional aspects of writing development processes? Journal of Academic Writing, 8(2), 202-211. https://doi.org/10.18552/joaw.v8i2.487

Grawe, N. D., \& Rutz, C. A. (2009). Integration with writing programs: A strategy for quantitative reasoning program development. Numeracy: Advancing Education in Quantitative Literacy, 2(2), 1-18. https://doi.org/10.5038/1936-4660.2.2.2

Grawe, P. H., \& Grawe, R. J. (2014). Reflections on the introduction of quantitative assessment in persuasive writing classes. Numeracy: Advancing Education in Quantitative Literacy, 7(1), 1-11. https://doi.org/10.5038/1936-4660.7.1.5

Hanauer, D. I. (2012). Meaningful literacy: Writing poetry in the language classroom. Language Teaching, 45(1), 105-115. https://doi.org/10.1017/S0261444810000522

Hanauer, D. I., \& Dolan, E. L. (2014). The project ownership survey: Measuring differences in scientific inquiry experiences. CBE-Life Sciences Education, 13, 149-158. https://doi.org/10.1187/cbe.13-06-0123

Hanauer, D. I., \& Englander, K. (2011). Quantifying the burden of writing research articles in a second language: Data from Mexican scientists. Written Communication, 28(4), 403416. https://doi.org/10.1177/0741088311420056

Hanauer, D. I., Sheridan, C. L., \& Englander, K. (2019). Linguistic injustice in the writing of research articles in English as a second language: Data from Taiwanese and Mexican researchers. Written Communication, 36(1), 136-154. https://doi.org/10.1177/0741088318804821

Hazari, Z., Potvin, G., Cribbs, J. D., Godwin, A., Scott, T. D., \& Klotz, L. (2017). Interest in STEM is contagious for students in biology, chemistry, and physics. Science Advances, 3(8). https://doi.org/10.1126/sciadv.1700046

Hillyard, C. (2012). Comparative study of the numeracy education and writing across the curriculum movements: Ideas for future growth. Numeracy: Advancing Education in Quantitative Literacy, 5(2), 1-19. https://doi.org/10.5038/1936-4660.5.2.2

Hunma, A., Arend, M., Nomdo, G., Hutchings, C., \& Samson, S. (2019). Revisiting writer identities in discomforting spaces: The envisioned self in writing. Alternation: Interdisciplinary Journal for the Study of the Arts and Humanities in South Africa, 26(2), 89-116. https://doi.org/10.29086/2519-5476/2019/v26n2a5

Inman, J. O., \& Powell, R. A. (2018). In the absence of grades: Dissonance and desire in course-contract classrooms. College Composition and Communication, 70(1), 30-56.

Ivanič, R. (1998). Writing and identity: The discoursal construction of identity in academic writing.John Benjamins.

Kaufman, R. A. (2017). Holistic learning for real-life writers: A call for affective pedagogy in firstyear composition. In L. Craton, R. Love, \& S. Barnette (Eds.), Writing pathways to student success (pp. 65-73). The WAC Clearinghouse.

Keranen, N., Encinas, F., \& Bazerman, C. (2012). Immersed in the game of science: Beliefs, emotions, and strategies of NNES scientists who regularly publish in English. In C. Bazerman, C. Dean, J. Early, K. Lunsford, S. Null, P. Rogers, \& A. Stansell (Eds.), International advances in writing research: Cultures, places, measures (pp. 387-402). The WAC Clearinghouse. 
Lin, H.-S., Hong, Z.-R., \& Huang, T.-C. (2012). The role of emotional factors in building public scientific literacy and engagement with science. International Journal of Science Education, 34(1), 25-42. https://doi.org/10.1080/09500693.2010.551430

Linnenbrink-Garcia, L., \& Pekrun, R. (2011). Students' emotions and academic engagement: Introduction to the special issue. Contemporary Educational Psychology, 36(1), 1-3. https://doi.org/10.1016/i.cedpsych.2010.11.004

Meisels, G. G. (2010). Science literacy: Hand in glove with numeracy. Numeracy: Advancing Education in Quantitative Literacy, 3(2), 1-3. https://doi.org/10.5038/1936-4660.3.2.1

Micciche, L. R. (2007). Doing emotion: Rhetoric, writing, teaching. Boynton/Cook.

Miller, J. E. (2010). Quantitative literacy across the curriculum: Integrating skills from English composition, mathematics, and the substantive disciplines. Educational Forum, 74(4), 334-346. https://doi.org/10.1080/00131725.2010.507100

Nicholes, J. (2019). How STEM majors' evaluations of quantitative literacy relate to their imagined STEM-career futures. Across the Disciplines, 16(2), 1-15.

Prebel, J. (2016). Engaging a 'pedagogy of discomfort': Emotion as critical inquiry in community-based writing courses. Composition Forum, 34.

https://compositionforum.com/issue/34/discomfort.php

President's Council of Advisors on Science and Technology (PCAST). (2012). Engage to excel: Producing one million additional college graduates with degrees in science, technology, engineering and mathematics.

https://www.whitehouse.gov/sites/default/files/microsites/ostp/fact sheet final.pdf

Reinholz, D. L., Matz, R. L., Cole, R., \& Apkarian, N. (2019). STEM is not a monolith: A preliminary analysis of variations in STEM disciplinary cultures and implications for change. CBE—Life Sciences Education, 18(4). https://doi.org/10.1187/cbe.19-02-0038

Robbins, S. B., Oh, I.-S., Le, H., \& Button, C. (2009). Intervention effects on college performance and retention as mediated by motivational, emotional, and social control factors: Integrated meta-analytic path analyses. Journal of Applied Psychology, 94(5), 1163-1184. https://doi.org/10.1037/a0015738

STEM education data. (2014). https://www.nsf.gov/nsb/sei/edTool/data/college-14.html

Tinto, V. (2017). Through the eyes of students. Journal of College Student Retention: Research, Theory, and Practice, 19(3), 254-269. https://doi.org/10.1177/1521025115621917

Trujillo, G., \& Tanner, K. D. (2014). Considering the role of affect in learning: Monitoring students' self-efficacy, sense of belonging, and science identity. CBE - Life Sciences Education, 13(1), 6. https://doi.org/10.1187/cbe.13-12-0241

van der Hoeven Kraft, K. J., Srogi, L., Husman, J., Semken, S., \& Fuhrman, M. (2011). Engaging students to learn through the affective domain: A new framework for teaching in the geosciences. Journal of Geoscience Education, 59(2), 71-84. https://doi.org/10.5408/1.3543934a

Wardle, E., Updike, A., \& Glotfelter, A. (2018). Using threshold concepts and disciplinary teams as the backbone of WAC seminars. Paper presented at the IWAC 2018, Auburn University, Auburn, AL.

Wilkins, J. L. (2000). Preparing for the 21st century: The status of quantitative literacy in the United States. School Science and Mathematics, 100(8), 405-418.

https://doi.org/10.1111/j.1949-8594.2000.tb17329.x 
Wolfe, J. (2010). Rhetorical numbers: A case for quantitative writing in the composition classroom. College Composition and Communication, 61(3), 452-475. 


\section{Appendix A. Writing Comfort Survey.}

1. In what department or program are you studying?

- Biochemistry

- Biology

- Chemistry

- Computer Science

- Geoscience

- Mathematics

- Physics

- Another

2. At what level are you studying?

- $\mathrm{PhD}$

- Master's

- Bachelor's

- Associate's

- Another

3. With what gender do you most identify?

- Male

- Female

- Another

- Prefer not to answer

4. How old are you?

- $18-25$

- 26-35

- $36-45$

- 46-55

- 56-above

- Prefer not to answer

5. What is your comfort level with each of these? $(1=$ Not at all comfortable; $2=$ Somewhat uncomfortable; 3 = Neither comfortable nor uncomfortable; $4=$ Somewhat comfortable; $5=$ Very comfortable)

- Working with numbers

- Writing about numbers

- Writing essays in my major

- Writing in general 